\title{
PENGARUH PROSES SINTERING TERHADAP PERUBAHAN DENSITAS, KEKERASAN DAN MIKROSTRUKTUR PELET U-ZrH
}

\author{
Masrukan, Mujinem \\ Pusat Teknologi Bahan Bakar Nuklir-BATAN \\ Kawasan Puspiptek, Serpong, Tangerang Selatan, 15314 \\ e-mail: masrukan2006@yahoo.com
}

(Naskah diterima : 21-12-2015, Naskah direvisi: 12-01-2016, Naskah disetujui: 21-01-2016)

\begin{abstract}
ABSTRAK
PENGARUH PROSES SINTERING TERHADAP PERUBAHAN DENSITAS, KEKERASAN DAN MIKROSTRUKTUR PELET U-ZrH $\mathbf{r H}_{\mathbf{x}}$. Proses sintering pelet bahan bakar U-ZrH $\mathrm{H}_{\mathrm{x}}$ dilakukan untuk memperoleh densitas yang lebih tinggi dari pelet sebelum disinter. Mula-mula dibuat pelet $\mathrm{U}-\mathrm{ZrH}_{\mathrm{x}}$ dari kandungan $\mathrm{Zr}$ berturut-turut sebesar $35 \%, 45 \%$ dan 55\% berat. Proses sintering dilakukan selama 1 jam pada temperatur yang bervariasi $1100{ }^{\circ} \mathrm{C}, 1200{ }^{\circ} \mathrm{C}$ dan $1300{ }^{\circ} \mathrm{C}$ dengan laju kenaikan temperaur $2{ }^{\circ} \mathrm{C} /$ menit, kemudian diturunkan temperaturnya dengan laju penurunan temperatur $10{ }^{\circ} \mathrm{C} /$ menit hingga temperatur kamar. Pelet $\mathrm{U}-\mathrm{ZrH}_{\mathrm{x}}$ yang telah disinter selanjutnya dikenai berbagai pengujian, antara lain dimensi, densitas, kekerasan, dan mikrostruktur. Pada pengujian densitas terlihat bahwa pada komposisi Zr yang sama tetapi temperatur sintering yang semakin tinggi maka terjadi kenaikan nilai densitas. Apabila dilihat pada temperatur sintering yang sama dan kandungan $\mathrm{Zr}$ yang semakin tinggi maka densitas yang diperoleh semakin rendah. Hasil pengujian kekerasan mikro menunjukkan bahwa pada komposisi tetap $\mathrm{Zr}$ sebesar $35 \%$ dan $55 \%$ yang disinter pada temperatur sintering yang semakin tinggi maka semakin tinggi kekerasannya, kemudian menurun bila temperatur sintering naik. Apabila dilihat hasil pengujian pada temperatur sintering tetap tetapi kandungan $\mathrm{Zr}$ berbeda maka terlihat dari kandungan $\mathrm{Zr}$ $35 \%\left(\mathrm{U}-35 \mathrm{ZrH}_{\mathrm{x}}\right)$ menjadi $45 \%\left(\mathrm{U}-45 \mathrm{ZrH}_{\mathrm{x}}\right)$ terjadi kenaikan kekerasan, dan akan menurun pada kenaikan kandungan $\mathrm{Zr}$ menjadi $55 \%\left(\mathrm{U}-55 \mathrm{ZrH}_{\mathrm{x}}\right)$. Sementara itu, dari hasil pemeriksaan mikrostruktur menunjukkan bahwa pada kompsisi $\mathrm{Zr}$ tetap tetapi temperatur sintering semakin tinggi, maka jarak antar serbuk semakin rapat. Apabila dilihat dari temperatur sintering tetap tetapi komposisi $\mathrm{Zr}$ yang semakin tinggi, maka terlihat bahwa semakin tinggi komposisi $\mathrm{Zr}$ semakin berkurang kerapatan jarak antar serbuk di dalam pelet. Dapat disimpulkan bahwa proses sintering pelet akan menaikkan densitas, kekerasan, dan kerapatan jarak antar serbuk. Kondisi optimum dicapai pada proses sintering pelet dengan komposisi $\mathrm{Zr} 45 \%\left(\mathrm{U}-45 \mathrm{Zr} \mathrm{H}_{\mathrm{x}}\right)$ yang disinter pada temperatur $1200{ }^{\circ} \mathrm{C}$. Pada kondisi tersebut pelet sinter mempunyai densitas sebesar $8,673 \mathrm{~g} / \mathrm{cm}^{3}$, kekerasan sebesar $661 \mathrm{HVN}$ tanpa mengalami keretakan.
\end{abstract}

Kata kunci: Sintering, densitas, kekerasan, mikrostruktur, pelet $\mathrm{U}-\mathrm{ZrH}_{\mathrm{x}}$. 


\section{ABSTRACT}

EFFECT OF SINTERING PROCESS TO CHANGES IN, DENSITY, HARDNESS, AND MICROSTRUCTURE OF $\boldsymbol{U}-\mathbf{Z r H}_{\mathbf{x}}$ PELET. The process of sintering fuel pellets $\mathrm{U}$-ZrHx performed to obtain a higher density compared pellets before sintered. At first, $\mathrm{U}-\mathrm{ZrH}_{x}$ pellets made from the content of $\mathrm{Zr}$ respectively $35 \%, 45 \%$ and $55 \%$ by weight. Sintering process is carried out for 1 hour at varying temperature $1100^{\circ} \mathrm{C}, 1200^{\circ} \mathrm{C}$ and $1300^{\circ} \mathrm{C}$ with an increase rate of $2^{\circ} \mathrm{C}$ temperatur/ min, then lowered the temperature at a rate of decrease in temperature of $10^{\circ} \mathrm{C} /$ min until room temperature. $\mathrm{U}-\mathrm{ZrH}_{x}$ pellets that have been sintered subsequently subjected to various tests, such as: the dimensions, density, hardness, and microstructure. In testing the density, it appears that at the same Zr composition but the sintering temperature is higher then an increase in the density. When seen in the same sintering temperature and Zr content is higher then the lower the density obtained. Micro hardness testing results show that the composition $\mathrm{Zr}$ $35 \%$ fixed and 55\% were sintered at the sintering temperature is higher, have the higher the hardness, and then decreases as the sintering temperature increase. If the test results viewed in the sintering temperature fixed but the content of $Z r$ is different, it can be seen from the content of $\mathrm{Zr} 35 \%\left(\mathrm{U}-35 \mathrm{ZrH}_{x}\right)$ to $45 \%\left(\mathrm{U}-45 \mathrm{ZrH}_{x}\right)$ an increase in hardness, and will decrease to an increase in the content of $\mathrm{Zr}$ to $55 \%\left(\mathrm{U}-55 \mathrm{Zr} \mathrm{H}_{\mathrm{x}}\right)$. Meanwhile, the results of the microstructure observation of the pellets can be seen that at composition Zr fixed but the sintering temperature is higher, then the distance between the powder / porosity increasingly dense. When viewed from the sintering temperature fixed but the composition increasingly higher Zr it is seen that higher Zr composition, the density between the powder in the pellets decreased. It can be concluded that the sintering process the pellets will increase density, hardness, and distance between powder increasingly dense. The optimum condition is achieved at sintering process the pellets with a composition of $45 \% \mathrm{Zr}\left(\mathrm{U}-45 \mathrm{Zr} \mathrm{H}_{x}\right)$ sintered at temperatures of $1200^{\circ} \mathrm{C}$. In these conditions the sintered the pellets has a density of $8.673 \mathrm{~g} / \mathrm{cm}^{3}$, hardness of $661 \mathrm{HVN}$ without developing cracks.

Keywords: $\quad$ Sintering, density, hardness, microstructure, $\mathrm{U}-\mathrm{ZrH}_{\mathrm{x}}$ pellet. 


\section{PENDAHULUAN}

Pusat Teknologi Bahan Bakar Nuklir (PTBBN) pada saat ini sedang melakukan pengembangan bahan bakar untuk PWR Pressurized Water Reactor) dari bahan keramik $\mathrm{UO}_{2}$, dan paduan $\mathrm{U}-\mathrm{Zr}$. Paduan $\mathrm{U}-\mathrm{Zr}$ dapat dikembangkan untuk bahan bakar reaktor riset $(\mathrm{U}-\mathrm{Zr})$ maupun untuk reaktor daya dalam bentuk hidrida $\left(\mathrm{U}-\mathrm{ZrH}_{\mathrm{x}}\right)$ yang digunakan sebagai bahan bakar reaktor jenis PWR. Pengembangan bahan bakar PWR baik $\mathrm{UO}_{2}$ maupun jenis yang lain dilakukan untuk meningkatkan unjuk kerja melalui peningkatan burn up (derajat bakar) karena dengan meningkatnya burn up maka akan menurunkan kebutuhan bahan bakar baru per energi yang dihasilkan [1]. Penggunaan bahan bakar paduan $\mathrm{U}-\mathrm{Zr}$ telah lama digunakan secara luas, seperti untuk bahan bakar reaktor TRIGA (Training Isotop by General Atommic) dalam bentuk $\mathrm{U}-\mathrm{ZrH}_{\mathrm{x}}$, Advance Boiling Water Reactor (ABWR), FBR (Fast Bredeer Reaktor) dan EBR (Experiment Breeder Reactor) yang mana dibuat dalam bentuk campuran antara U, Pu dan $\mathrm{Zr}{ }^{[2,3]}$.

Rancangan bahan bakar baru untuk PWR telah diusulkan untuk mengganti bahan bakar jenis $\mathrm{UO}_{2}$ dengan uranium hidrida $\left(\mathrm{U}-\mathrm{ZrH}_{\mathrm{x}}\right)$, dimana dalam rancangan bahan bakar baru tersebut dapat ditempatkan hidrogen sebagai moderator secara langsung di dalam bahan bakar yang memungkinkan reaktor dapat beroperasi pada temperatur yang relatif tinggi (hingga $750{ }^{\circ} \mathrm{C}$ ) serta mempunyai sifat termal lebih baik dibanding bahan bakar keramik ${ }^{[4]}$. Penggunaan uranium dalam bahan bakar uranium hidrida $\left(\mathrm{U}-\mathrm{ZrH}_{\mathrm{x}}\right)$ relatif lebih sedikit dibandingkan dengan bahan bakar jenis lain seperti bahan bakar keramik $\mathrm{UO}_{2}$. Hal ini merupakan kelebihan yang dimiliki bahan bakar uranium jenis hidrida tersebut dan berdampak langsung terhadap nilai ekonomis.

Rancangan PWR yang menggunakan bahan bakar $\mathrm{U}-\mathrm{ZrH}_{\mathrm{x}}$ diusulkan oleh perusahaan General Atomic dari USA dan dikenal sebagai reaktor TPS (Triga Power
System), dimana dalam desain tersebut reaktor dapat menghasilkan daya sebesar $64 \mathrm{MWt} / 1,4 \mathrm{MWe}$ dengan menggunakan uranium berpengkayaan rendah ${ }^{235} \mathrm{U}$ sebesar $19,9 \%$ [5]. Pengembangan bahan bakar paduan uranium zirkonium selain ditujukan untuk mendapatkan bahan bakar PWR juga diarahkan untuk dapat lanjut menjadi bahan bakar reaktor generasi ke IV[6]. Pengembangan bahan bakar PWR berbasis $\mathrm{U}-\mathrm{ZrH}_{\mathrm{x}}$ telah dikembangkan oleh PTBBN melalui bantuan pendanaan riset oleh Kementerian Riset dan Teknologi, dimana dalam riset tersebut telah dibuat ingot hingga menjadi pelet mentah (green pellet) $\mathrm{U}-\mathrm{ZrH}_{\mathrm{x}}$ dalam komposisi $\mathrm{Zr} 35 \%$, $45 \%$ dan $55 \%$ dan telah dilakukan pengujian untuk mendapatkan pelet mentah yang memenuhi persyaratan untuk diproses lebih lanjut menjadi bahan bakar PWR ${ }^{[7]}$. Untuk membuat bahan bakar U-ZrH $\mathrm{ZH}_{\mathrm{x}}$ yang berbentuk pelet, mula-mula dilakukan pembuatan serbuk $\mathrm{U}-\mathrm{ZrH}_{\mathrm{x}}$ dari ingot paduan $\mathrm{U}-\mathrm{Zr}$ dengan menggunakan teknik hidriding dimana dalam teknik hidriding tersebut hidrogen akan bereaksi dengan logam $\mathrm{Zr}$ membentuk hidrida yang rapuh sehingga mudah dibuat menjadi serbuk dengan cara ditumbuk. Serbuk U- $\mathrm{ZrH}_{\mathrm{x}}$ yang diperoleh selanjutnya dibuat pelet dengan teknik pengepresan pada tekanan 4-5 ton, dan selanjutnya dilakukan proses sintering pada berbagai variasi temperatur sintering. Tujuan dari penelitian ini adalah untuk mendapatkan parameter proses dalam pembuatan pelet $\mathrm{U}-\mathrm{ZrH}_{\mathrm{x}}$ yang mempunyai densitas tinggi.

Pembuatan pelet $\mathrm{U}-\mathrm{ZrHx}$ dilakukan dengan teknik metalurgi serbuk. Metalurgi serbuk adalah salah satu proses manufaktur barang komersil dari bahan logam dengan bahan berbentuk serbuk. Prinsip dari proses ini adalah dengan memadatkan bahan yang telah berbentuk serbuk dengan cara menekan (compaction) kemudian untuk selanjutnya dipanaskan dibawah titik lelehnya sehingga serbuk logam akan memadu karena adanya mekanisme transformasi massa akibat difusi dari atom-atom di permukaan serbuk yang disebut proses sintering. Dengan adanya 
difusi ini maka akan terbentuk ikatan-ikatan partikel yang halus antar permukaan serbuk yang dapat meningkatkan kekuatan dan sifat fisisnya [8]. Adapun proses metalurgi meliputi beberapa tahapan seperti, mixing, kompaksi dan sintering. Proses kompaksi adalah salah satu tahapan di dalam proses metalurgi serbuk yang dilakukan guna memadatkan serbuk dan membuat ikatan secara mekanik antar serbuk dengan memberikan tekanan dari luar terhadap serbuk yang telah dimasukkan ke dalam suatu cetakan yang memiliki bentuk sesuai dengan yang diinginkan, serbuk yang telah dikompaksi akan membentuk suatu komponen sesuai dengan bentuk dari cetakan itu sendiri. Proses kompaksi ini digunakan untuk mendapatkan densitas yang tinggi ${ }^{[8]}$.

Proses selanjutnya adalah sintering yaitu proses yang digunakan untuk membentuk ikatan antar partike atau serbuk setelah proses kompaksi. Proses ini dilakukan dengan memberikan panas dengan cara memanaskan sampel pada temperatur di bawah melting point-nya sehingga terjadi transfer massa pada permukaan serbuk dan terbentuk ikatan bersama antar serbuk ${ }^{[8]}$. Tahapan sintering dibagi menjadi tiga tahap yakni [9,10]: sebagai tahap awal (initial stage), dimana proses sintering berawal pada titik kontak antar partikel serbuk, kemudian titik kontak tersebut bertambah luas dan membentuk neck atau leher. Neck ini kemudian menjadi batas butir atau grainboundary. Pada saat yang bersamaan, rongga antar partikel serbuk mengecil dan membentuk por. Tahap pertengahan (intermediate stage) atau tahap kedua adalah dimana pada tahap ini batas butir membesar dan pori-porinya mengecil dengan cepat. Akibatnya pelet mengalami proses shringkage atau pengerutan dan densitasnya menjadi meningkat tajam. Hal ini terjadi selama kenaikan temperatur dari $300^{\circ} \mathrm{C}$ hingga mencapai temperatur puncak (1100, 1200, dan $1300^{\circ} \mathrm{C}$ ). Disini terjadi densifikasi secara cepat karena adanya interaksi antar pori dan batas butir. Selama pertumbuhan butir (grain growth) akan terjadi pori-pori dapat dikeluarkan oleh pergerakan batas butir sehingga densitas pelet mengalami penigkatan. Pori-pori tersebut ditinggalkan oleh pergerakan batas butir dalam butir, sehingga densitas pelet tetap dan sebagai tahap akhir (final stage). Tahap ini berlangsung selama soaking time atau selama pelet pada temperatur puncak. Densifikasi pelet berlangsung lambat karena yang terjadi hanya perubahan bentuk dan pengecilan poripori dalam butir. Parameter sintering yang sangat berpengaruh terhadap kualitas hasil dianta-ranya adalah: temperatur, waktu penahanan, kecepatan pendinginan, kecepatan pema-nasan, jenis materia dan atmosfir tungku [11,12].

Dalam penelitian ini akan dicoba untuk melakukan percobaan sintering dengan menggunakan temperatur sintering yang bervariasi pada pelet $\mathrm{U}-\mathrm{ZrH}_{\mathrm{x}}$ dengan kandungan $\mathrm{Zr}$ bertutut-turut sebesar $35 \%$, $45 \%$, dan $55 \%$ untuk selanjutnya diamati perubahan yang terjadi terhadap densitas, kekerasan dan mikrostruktur. Dari penelitian ini diharapkan dapat diperoleh parameter temperatur sintering yang optimum dalam membuat pelet sehingga memenuhi persyaratan sebagai bahan bakar PWR.

\section{METODOLOGI}

Pelet $\mathrm{U}-\mathrm{ZrH}_{\mathrm{x}}$ dibuat dengan cara melakukan pengepresan serbuk $\mathrm{U}-\mathrm{ZrH}_{\mathrm{x}}$ yang diperoleh dari proses hidriding $\mathrm{U}-\mathrm{Zr}$ yang mempunyai komposisi $\mathrm{Zr}$ berturut-turut sebesar $35 \%, 45 \%$ dan $55 \%$. Proses pengepresan sebuk $\mathrm{U}-\mathrm{ZrH}_{\mathrm{x}}$ dilakukan dengan menggunakan mesin press yang beroperasi pada tekanan press sebesar antara 4-5 Ton. Serbuk $\mathrm{U}-\mathrm{ZrH}_{\mathrm{x}}$ sebelum dipress terlebih dahulu dicampur dengan binder zinc stearat kemudian dimasukkan ke dalam cetakan (dies), selanjutnya dilakukan pengepresan. Serbuk U-ZrHx yang telah dipress menjadi pelet selanjutnya diukur dimensinya meliputi panjang, diameter, dan berat secara manual. Langkah selanjutnya adalah melakukan proses sintering di dalam sebuah tungku sinter dan dalam suasana gas inert nitrogen $\left(\mathrm{N}_{2}\right)$. 
Pelaksanaan proses sintering dilakukan pada temperatur yang bervariasi yakni pada $1100{ }^{\circ} \mathrm{C}, 1200{ }^{\circ} \mathrm{C}$ dan $1300{ }^{\circ} \mathrm{C}$ dengan laju kenaikan tempeatur $2{ }^{\circ} \mathrm{C} / \mathrm{min}$, waktu penahanan (soaking time) selama 1 jam, dan laju penurunan temperatur $10^{\circ} \mathrm{C} / \mathrm{min}$. Selama proses sintering dilakukan, gas nitrogen dialirkan ke dalam tungku untuk mengusir oksigen yang ada sehingga pelet tidak mengalami oksidasi atau bahkan terbakar. Setelah proses sintering dan proses pendinginan dalam tungku selesai, pelet dikeluarkan dari dalam tugku dan dikenai pengujian-pengujian diantaranya pengujian dimensi, densitas, kekerasan dan mikrostruktur. Pengujian dimensi dilakukan secara manual dengan menggunakan jangka sorong dan timbangan, pengujian densitas dilakukan dengan menggunakan peralatan piknometer, pengujian kekerasan dengan mengunakan peralatan kekerasan mikro (Vickers), dan mikrostruktur pelet dengan menggunakan mikroskop optik. Gambar 1 dapat diketahui dan diperlihatkan skema mekanisme proses sintering dan Gambar 2 merupakan contoh gambar pelet hasil sintering.

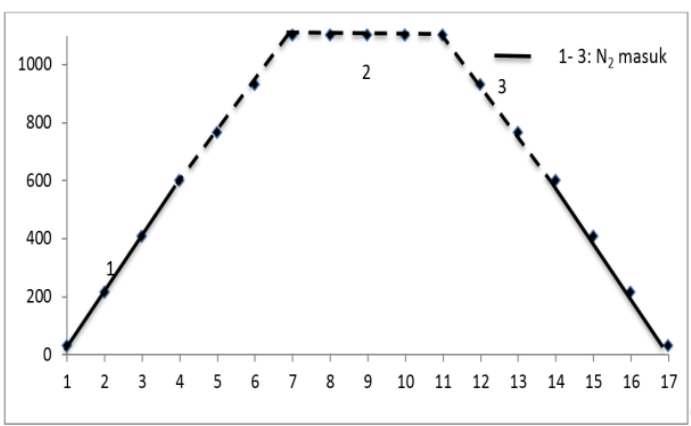

Gambar 1. Skema jalannya proses sintering

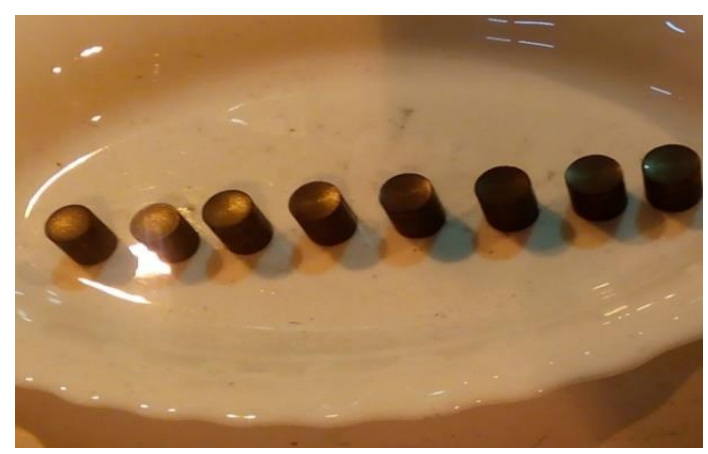

Gambar 2. Contoh pelet U-ZrH $\mathrm{Zn}_{\mathrm{x}}$ hasil proses sintering

\section{HASIL DAN PEMBAHASAN}

Hasil pengukuran densitas pelet menggunakan piknometer ditampilkan pada Gambar 3 dan 4, kekerasan pada Gambar 5, dan mikrostruktur pada Gambar 6 hingga 14.

\section{a. Pengujian densitas pelet mentah (green pellet)}

Pengujian densitas sebelum disinter dilakukan secara manual dan menggunakan auto pycnometer ditampilkan pada Gambar 3. Pengujian densitas secara manual dilakukan dengan menggunakan jangka sorong dengan cara mengukur ketinggian dan diameter pelet serta menimbang berat dari pelet tersebut. Gambar 3 memperterlihatkan bahwa hasil pengujian densitas menggunakan auto pycnometer mempunyai nilai yang lebih tinggi dibandingkan cara secara manual. Sebagai contoh pada pelet $\mathrm{U}-35 \mathrm{ZrH}_{\mathrm{x}}$ mempunyai densitas sebesar $5,214 \mathrm{~g} / \mathrm{cm}^{3}$ yang diukur dengan cara manual sedangkan pada pengukuran dengan menggunakan auto pycnometer mempunyai densitas sebesar $9,914 \mathrm{~g} / \mathrm{cm}^{3}$. Hal ini disebabkan karena pada pengukuran dengan menggunakan cara manual dilakukan dengan mengukur bagian luar pelet sehingga menghasilkan hasil pengukuran (volume) yang lebih besar dari volume yang sebenarnya. Sementara itu, pada pengukuran dengan menggunakan peralatan auto pycnometer yang menggunakan gas $\mathrm{He}$ maka gas He akan mudah mengadakan penetrasi ke dalam pelet hingga melewati porositas sehingga menghasilkan hasil pengukuran (volume) yang lebih kecil. Oleh karena pada pengukuran dengan auto pycnometer yang mempunyai volume lebih kecil dan apabila digunakan untuk membagi berat sampel yang sama maka akan menghasilkan nilai densitas yang lebih besar. Hasil tersebut bila dibandingkan dengan hasil pengukuran densitas pada pembuatan pelet sebelum disinter (green pellet) yang pernah dilakukan di Pusat Teknologi Bahan Bakar Nuklir dengan hasil yang tidak berbeda, yakni untuk pelet yang diukur secara manual diperoleh nilai densitas sebesar $6,7052 \mathrm{~g} / \mathrm{cm}^{3}$ 
sedangkan dengan menggunakan auto pycnometer diperoleh nilai densitas sebesar $10,43 \mathrm{~g} / \mathrm{cm}^{3}[2]$.

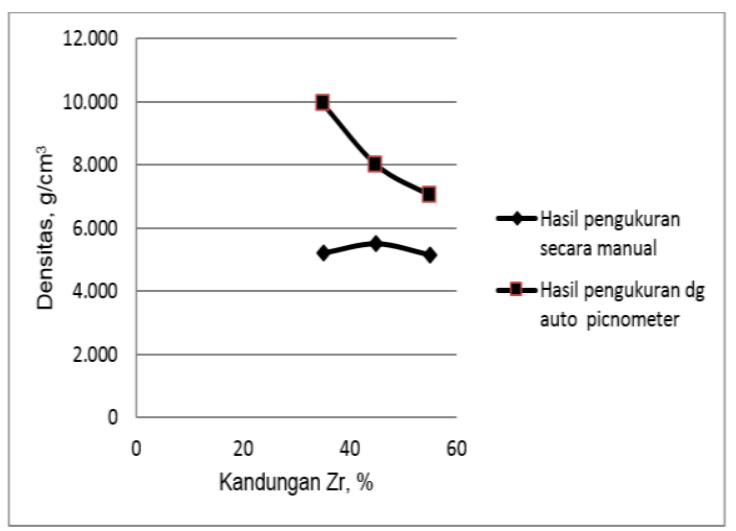

Gambar 3. Kurva pengujian densitas pelet sebelum disinter secara manual dan menggunakan auto pycnometer

\section{b. Pengujian densitas pelet hasil sintering}

Pada pengujian densitas hasil proses sintering yang dilakukan dengan menggunakan peralatan auto pycnometer seperti ditampilkan pada Gambar 4 terlihat bahwa pada komposisi $\mathrm{Zr}$ yang sama tetapi temperatur sintering yang semakin tinggi maka terjadi kenaikan nilai densitas. Sebagai contoh pada komposisi $\mathrm{Zr} \quad 35 \%\left(\mathrm{U}-35 \mathrm{ZrH} \mathrm{H}_{\mathrm{x}}\right)$ dan temperatur sintering sebesar $1100{ }^{\circ} \mathrm{C}$ densitas paduan U-35Zr sebesar $8,156 \mathrm{~g} / \mathrm{cm}^{3}$ menjadi sebesar $8,356 \mathrm{~g} / \mathrm{cm}^{3}$ bila temperatur sintering dinaikkan menjadi $1200{ }^{\circ} \mathrm{C}$. Hal ini dapat terjadi karena apabila temperatur sintering semakin tinggi maka butir-butir pelet akan mengalami pergerakan yang lebih besar karena semakin tinggi temperatur pemanasan maka energi dalam menjadi lebih besar pula. Butir-butir yang bergerak tersebut akan saling mendekati satu dengan lainnya sehingga porositas semakin berkurang. Akibatnya, jarak antar butir menjadi semakin rapat dan porositas menjadi semakin sedikit sehingga densitas yang diperoleh menjadi semakin tinggi. Porositas merupakan daerah kosong atau rongga yang terbentuk pada proses kompaksi yang menyebabkan adanya gas yang terjebak diantara serbuk saat proses sintering ${ }^{[13]}$. Adanya porositas di dalam suatu material akan sangat mempengaruhi sifat mekaniknya, hal ini disebabkan porositas akan menyebabkan adanya konsentrasi tegangan sehingga mudah berdeformasi plastis dan lokalisasi tegangan[13]. Apabila dilihat pada temperatur sintering yang sama dan semakin tinggi kandungan $\mathrm{Zr}$ maka densitas yang diperoleh semakin rendah. Hal ini disebabkan semakin tinggi kandungan $\mathrm{Zr}$ maka akan terbentuk hidrida $\left(\mathrm{ZrH}_{\mathrm{x}}\right)$ yang semakin banyak. Sebagai contoh pada temperatur sintering $1100{ }^{\circ} \mathrm{C}$ dan kandungan $\mathrm{Zr}$ 45\% mempunyai densitas sebesar $8,621 \mathrm{~g} / \mathrm{cm}^{3}$ maka pada kandungan $\mathrm{Zr} 55 \%$ nilai densitas menjadi sebesar $8,435 \mathrm{~g} / \mathrm{cm}^{3}$. Oleh karena hidrida $\mathrm{ZrH}_{\mathrm{x}}$ mempunyai densitas yang lebih rendah dibandingkan $\mathrm{U}-\mathrm{Zr}$ tanpa hidrida maka densitas $\mathrm{U}-\mathrm{ZrH}_{\mathrm{x}}$ yang diperoleh semakin rendah pula.

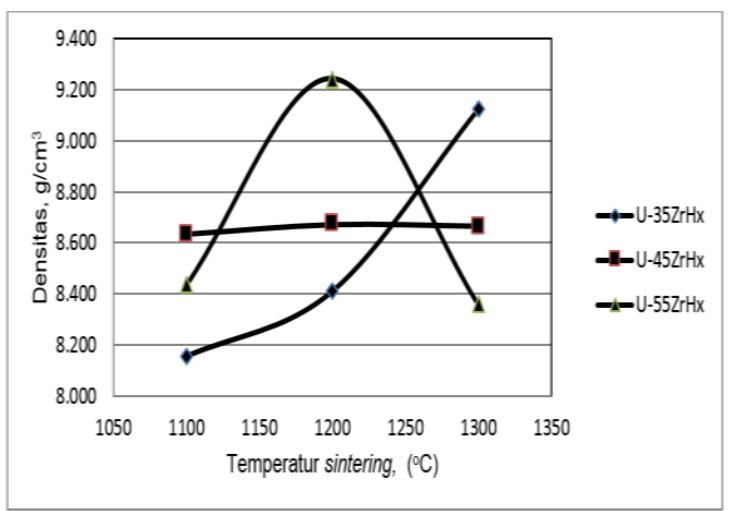

Gambar 4. Kurva densitas terhadap temperatur sintering $\mathrm{U}-\mathrm{ZrH}_{\mathrm{x}}$ menggunakan auto pycnometer

\section{c. Pengujian kekerasan}

Hasil pengujian kekerasan mikro dengan menggunakan metode Vickers ditampilkan pada Gambar 3. Gambar 3 menunjukkan bahwa pada komposisi tetap $\mathrm{Zr}$ sebesar $35 \%$ dan 55\% yang disinter pada temperatur sintering yang semakin tinggi maka kekerasan yang terjadi semakin tinggi, kemudian menurun bila temperatur sintering naik. Pada kompoisi kandungan $\mathrm{Zr}$ sebesar 35\% dan temperatur sintering sebesar $1100^{\circ} \mathrm{C}$, kekerasan pelet sebesar $357 \mathrm{HVN}$ menjadi sebesar 397 HVN bila temperatur sintering menjadi sebesar $1200^{\circ} \mathrm{C}$ kemudian menurun menjadi 278 HVN bila temperatur sintering menjadi $1300^{\circ} \mathrm{C}$. Kenaikan kekerasan ini 
disebabkan karena kenaikan temperatur sintering sehingga semakin rapat jarak antar serbuk dan semakin kecil porositas pada pelet sehingga pelet semakin padat dan menjadi semakin keras. Dari pengamatan secara visual pada pelet hasil sintering ternyata bahwa pada temperatur sintering $1300^{\circ} \mathrm{C}$ untuk pelet paduan $\mathrm{U}-35 \mathrm{ZrH}_{\mathrm{x}}$ dan $\mathrm{U}-55 \mathrm{ZrH}_{\mathrm{x}}$ mengalami kerusakan pada bagian pinggir atas yaitu sedikit pecah. Diharapkan pelet yang diperoleh mempunyai kekerasan yang tinggi tetapi tidak sampai rapuh dan mengakibatkan mudah retak/pecah. Hal ini diduga disebabkan pada temperatur pemanasan hingga $1300^{\circ} \mathrm{C}$ terjadi penyusutan yang cukup besar dan serbuk semakin besar serta antar serbuk saling menekan sehingga ruang untuk pergerakan serbuk sudah tidak ada lagi, akibatnya terjadi kerusakan/sedikit pecah ${ }^{[14]}$. Apabila dilihat hasil pengujian pada temperatur sintering tetap tetapi kandungan $\mathrm{Zr}$ berbeda maka terlihat dari kandungan $\mathrm{Zr} 35 \%\left(\mathrm{U}-35 \mathrm{ZrH} \mathrm{H}_{\mathrm{x}}\right)$ menjadi $45 \% \quad\left(\mathrm{U}-45 \mathrm{ZrH} \mathrm{H}_{\mathrm{x}}\right)$ terjadi kenaikan kekerasan, dan akan menurun pada kenaikan kandungan $\mathrm{Zr}$ mencaai $55 \% \quad\left(\mathrm{U}-55 \mathrm{ZrH} \mathrm{Z}_{\mathrm{x}}\right.$ ). Sebagai contoh, pada temperatur sintering $1100^{\circ} \mathrm{C}$ pelet paduan $\mathrm{U}-35 \mathrm{ZrH}_{\mathrm{x}}\left(\mathrm{U}-35 \mathrm{ZrH}_{\mathrm{x}}\right)$ mempunyai kekerasan sebesar $357 \mathrm{HVN}$, naik menjadi $765 \mathrm{HVN}$ bila kandungan $\mathrm{Zr}$ menjadi 45\% (U-45ZrH $\left.\mathrm{ZH}_{\mathrm{x}}\right)$ dan turun menjadi $278 \mathrm{HVN}$ bila kandungan $\mathrm{Zr}$ menjadi $55 \%\left(\mathrm{U}-55 \mathrm{ZrH}_{\mathrm{x}}\right)$. Keadaan ini disebabkan karena hingga kandungan $\mathrm{Zr}$ sebesar $45 \%$ serbuk yang terbentuk dalam bentuk hidrida $\mathrm{U}-\mathrm{ZrH}_{\mathrm{x}}$ semakin rapat sehingga pelet yang terbentuk semakin keras. Namun, pada kandungan $\mathrm{Zr}$ sebesar $55 \%$, serbuk pelet didominasi oleh hidrida $\mathrm{ZrH}_{\mathrm{x}}$ atau dengan lain kata hidrida yang ada semakin banyak dan pada proses sintering pada temperatur tetap butiran hidrida dengan jumlah yang lebih banyak dibandingkan pada kandungan $\mathrm{Zr} 35 \%$ dan $45 \%$ tersebut semakin kasar sehingga kerapatan serbuk lebih juga semakin rendah. Oleh karena kerapatan serbuk di dalam pelet semakin rendah maka kekerasan menjadi lebih rendah pula.

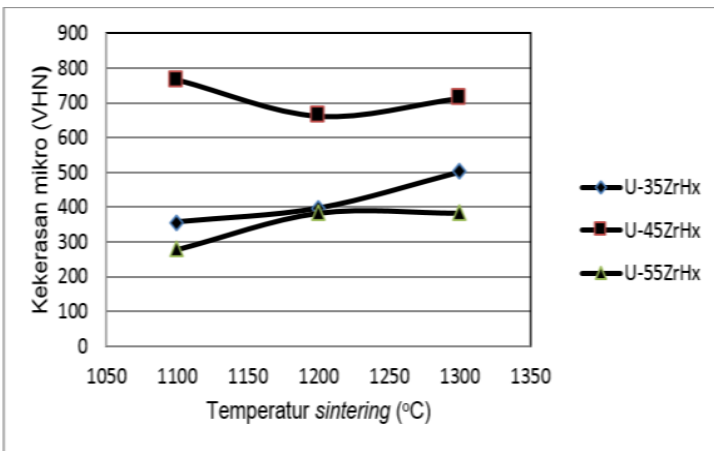

Gambar 5. Kurva kekerasan terhadap temperatur sintering $\mathrm{U}-\mathrm{ZrH}_{\mathrm{x}}$

\section{d. Mikrostruktur}

Hasil pemeriksaan mikrostruktur pelet sinter ditampilkan pada Gambar 6 hingga 14 Memperhatikan Gambar 6 hingga 14 terlihat bahwa pada komposisi $\mathrm{Zr}$ tetap tetapi temperatur sintering naik, maka jarak antar serbuk (porositas) yang terbentuk semakin rapat sebagai akibat dari proses kenaikan temperatur sintering. Proses sintering akan membuat serbuk bergerak sehingga jarak antar serbuk menjadi semakin rapat. Oleh karena jarak antar partikel semakin rapat sehingga porositas semakin berkurang. Dilihat dari proses sintering pada temperatur tetap tetapi komposisi $\mathrm{Zr}$ yang semakin tinggi maka terlihat bahwa semakin tinggi komposisi $\mathrm{Zr}$ semakin berkurang kerapatan jarak antar serbuk di dalam pelet. Dengan kata lain maka semakin besar porositas yang terjadi. Hal ini disebabkan bertambahnya kadar $\mathrm{Zr}$ mengakibatkan serbuk yang seharusnya membesar akan tertahan sehingga porositas menjadi besar. Penghambatan pertumbuhan serbuk dilakukan dengan cara menahan pergerakan batas serbuk. Selain itu, secara keseluruhan terlihat bahwa partikel $\mathrm{U}-\mathrm{ZrH}_{\mathrm{x}}$ berbentuk tidak teratur dan porous yang merupakan karakteristik serbuk hasil proses hidriding ${ }^{[8]}$.

Apabila dikaitkan antara mikrostruktur yang terjadi dengan sifat mekanik maupun fisik yakni kekerasan mikro dan densitas pelet, dapat dilihat bahwa pada komposisi $\mathrm{Zr}$ tetap tetapi temperatur sintering naik maka jarak antar serbuk di dalam pelet menjadi semakin rapat dan mengakibatkan kekerasan dan densitas pelet semakin tinggi. Sementara itu, 
pada temperatur tetap tetapi kandungan $\mathrm{Zr}$ semakin tinggi maka jarak antar serbuk di dalam pelet semakin lebar dan mengakibatkan kekerasan semakin rendah.

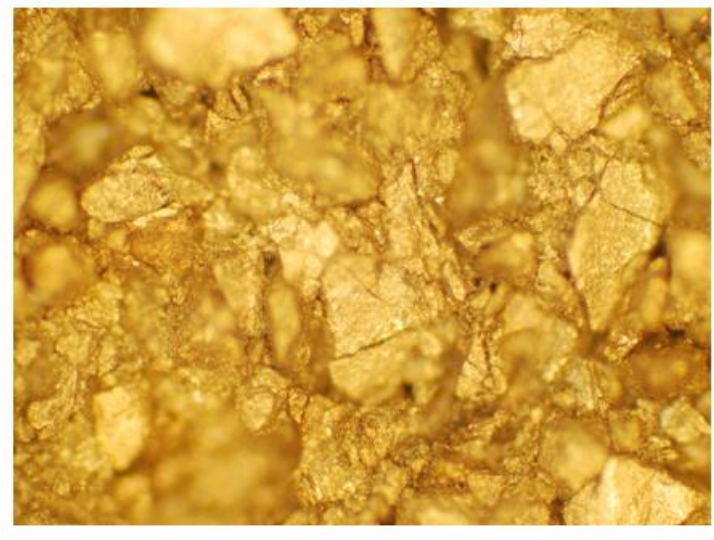

$12,5 \mu \mathrm{m}$

Gambar 6. Pelet U-35Zr, T sintering $1100^{\circ} \mathrm{C}$

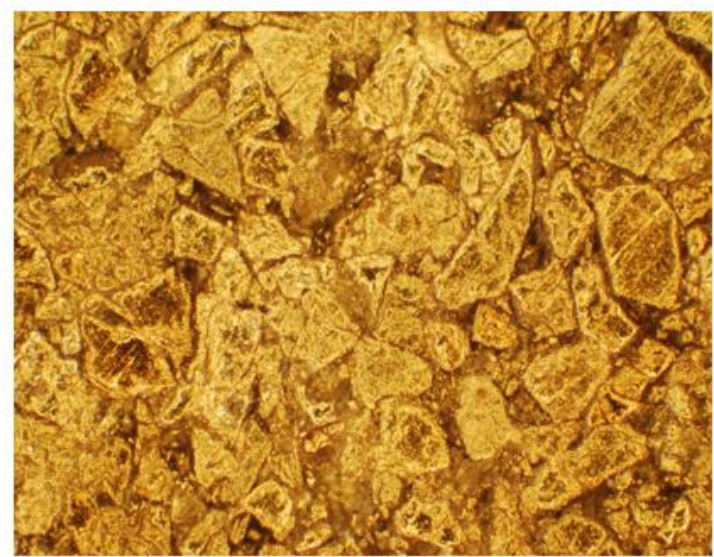

$12,5 \mu \mathrm{m}$

Gambar 7. Pelet U-35Zr, T sintering $1200^{\circ} \mathrm{C}$

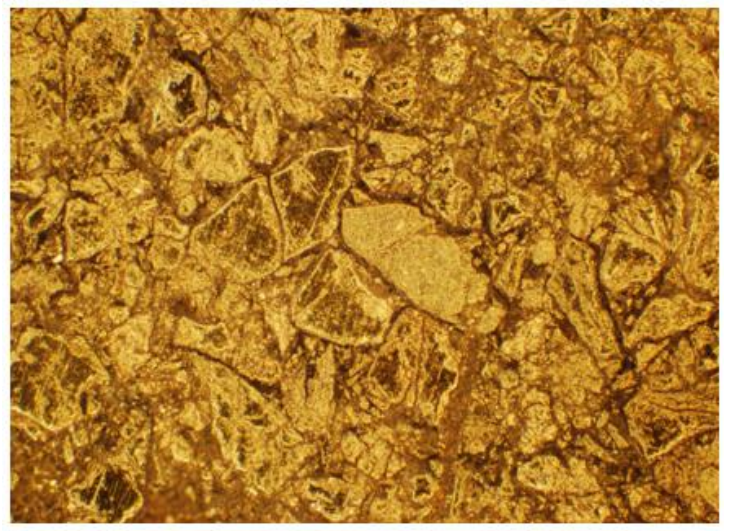

$12,5 \mu \mathrm{m}$

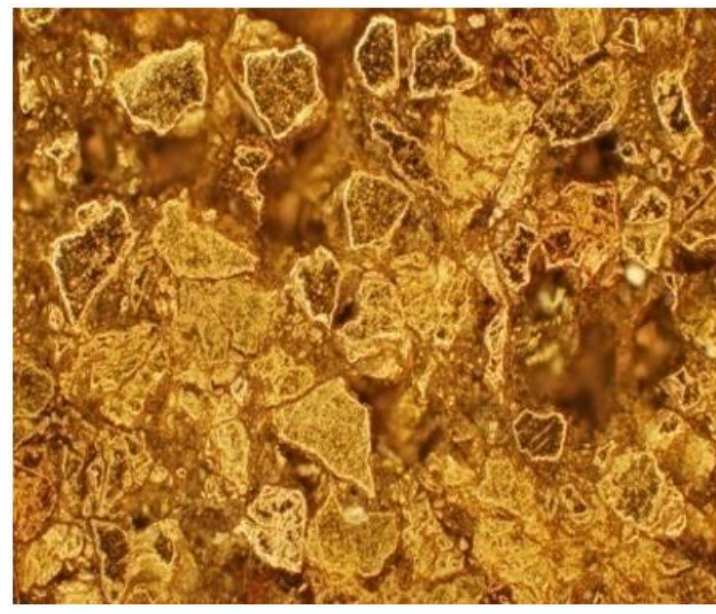

$12,5 \mu \mathrm{m}$

Gambar 9 . Pelet U-45Zr, T sintering $1100^{\circ} \mathrm{C}$

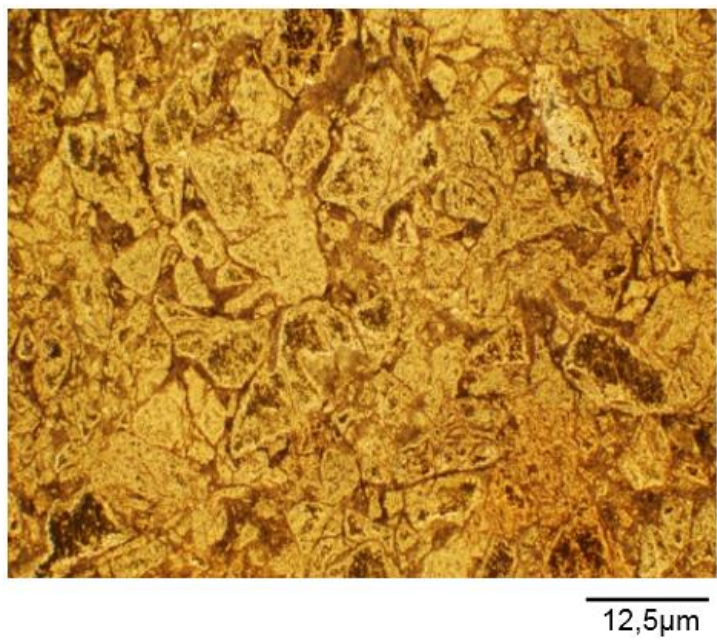

Gambar 9. Pelet U-45Zr, T sintering $1200{ }^{\circ} \mathrm{C}$

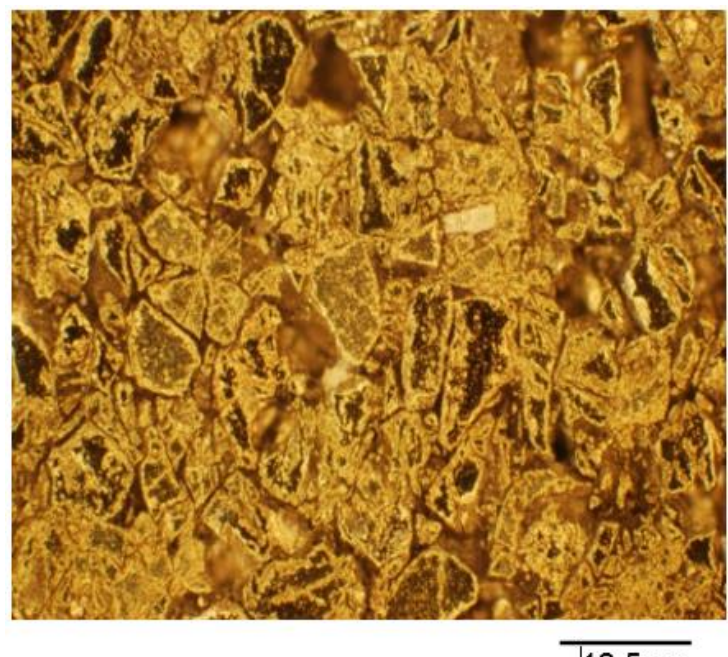

$12,5 \mu \mathrm{m}$

Gambar 10 . Pelet U-45Zr, T sintering $1300^{\circ} \mathrm{C}$

Gambar 8. Pelet U-35Zr, T sintering $1300^{\circ} \mathrm{C}$ 


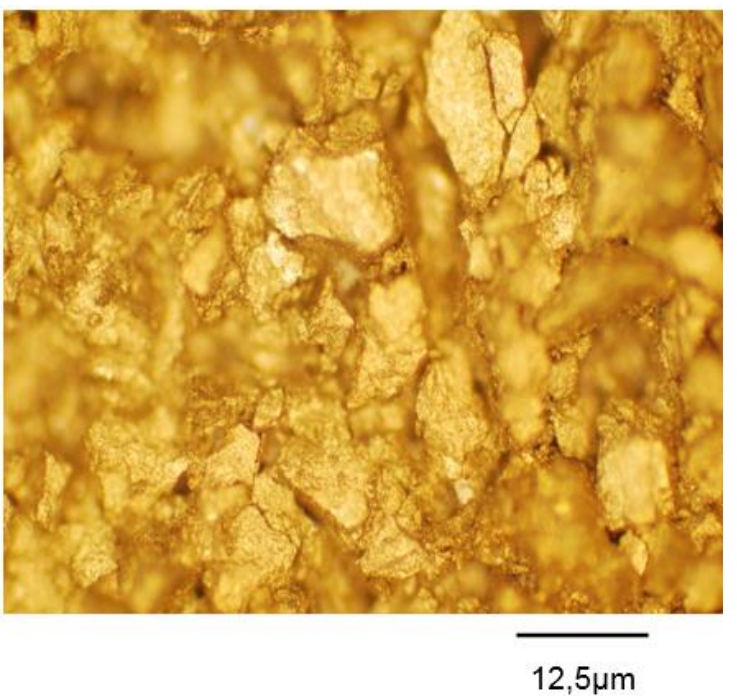

Gambar 11. Pelet U-55Zr, T sintering $1100{ }^{\circ} \mathrm{C}$

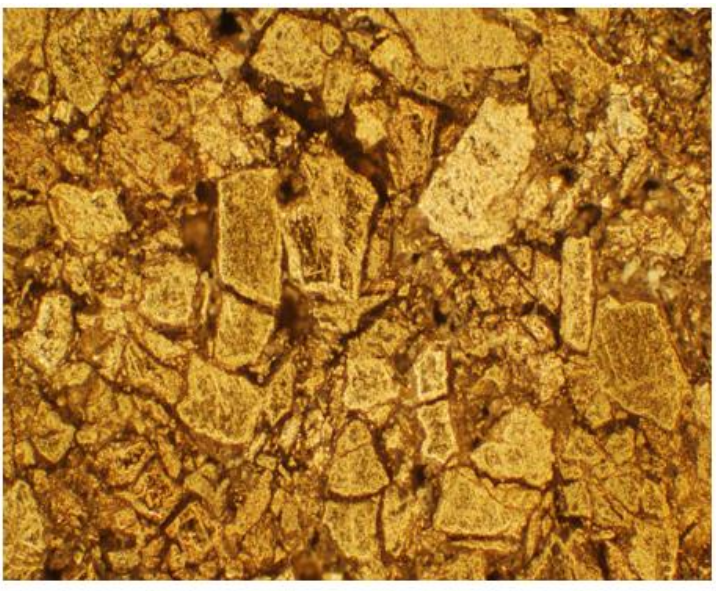

$12,5 \mu \mathrm{m}$

Gambar 12. Pelet U-55Zr, T sintering $1200^{\circ} \mathrm{C}$

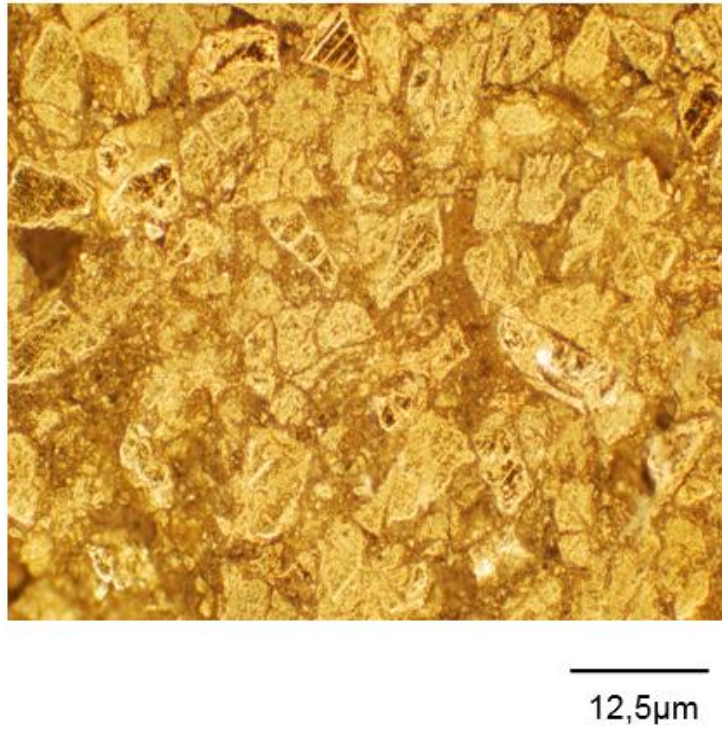

Gambar 13. Pelet U-55Zr, T sintering $1300^{\circ} \mathrm{C}$

\section{SIMPULAN}

Hasil pengujian hasil proses sintering pelet $\mathrm{U}-35 \mathrm{ZrH}_{\mathrm{x}}, \mathrm{U}-45 \mathrm{ZrH}_{\mathrm{x}}$ dan U-35ZrH pada berbagai temperatur sintering dapat disimpulkan bahwa semakin tinggi temperatur sintering maka densitas dan kekerasan pelet semakin tinggi. Sebagai contoh pada komposisi $\mathrm{Zr} 35 \%(\mathrm{U}-35 \mathrm{ZrH})$ dan temperatur sintering sebesar $1100^{\circ} \mathrm{C}$ maka nilai densitas paduan U-35Zr sebesar $8,156 \mathrm{~g} / \mathrm{cm}^{3}$ menjadi sebesar $8,356 \mathrm{~g} / \mathrm{cm}^{3}$ bila temperatur sintering dinaikkan menjadi $1200^{\circ} \mathrm{C}$, sedangkan kekerasan pelet berubah dari $357 \mathrm{HVN}$ menjadi sebesar 397 HVN. Pada pengamatan mikrostruktur terlihat bahwa apabila temperatur sintering semakin tinggi maka porositas pelet semakin rendah. Sebaliknya, pada tempe-ratur proses sintering tetap dan kandungan $\mathrm{Zr}$ semakin tinggi maka densitas dan kekerasan pelet semakin rendah sedangkan porositas yang terjadi semakin tinggi. Dari hasil proses sintering tersebut dapat dikatakan bahwa perubahan temperatur proses sintering akan mengakibatkan perubahan densitas, kekera-san dan mikrostruktur.

\section{UCAPAN TERIMA KASIH}

Penulis mengucapkan terima kasih yang sebesar-besarnya kepada teman-teman diantaranya Bpk Slamet P, Bpk.Suyoto, Bpk Mugiyono, dan Bpk yatno D.A yang telah membantu dalam penelitian ini. Juga penulis menyampaikan banyak terima kasih kepada Kementerian Ristek Dikti atas kesediaannya memberikan bantuan pendanaan dalam program Sinas 2015 sehingga penelitian dapat berjalan dengan lancar.

\section{DAFTAR PUSTAKA}

[1] Etty Mutiara, Tri Yulianto, (2013), Efek Penambahan Dopan Terhadap Karakteristik Pelet $\mathrm{UO}_{2}$ Sinter, Jurnal Daur Bahan Bakar Urania, Volume 19 No 2, Juni 2013, Hal. 85. ISSN No: 0852- 4777, Akreditasi No. 
395/AU2/P2MI-LIPI/04/2012.

[2] Masrukan, (2013), The Study of Manufacturing and Ingot Characterization of $U$ Zr Alloys, Journal of Aplied Mechanic and Material, Vol 376(2013), p 23-29, Trans Tech Publications. ISSN No. 1660- 9336, ISSN/ISO.

[3] Ahmed Abdelghafar Galahom, Ibrahim Ismail Bashter and Moustafa Aziz, (2013), Analysis of Neutronic Characteristics of Uranium Zirconium Hydride Fuel in Advanced Boiling Water Reactor, Journal of Materials Science and Engineering, A 3 (6) (2013). Hal. 437-442.

[4] Greenpan, Ehud, (1994). BWR Fuel Assembly Having Oxide and Hydride Fuel. US Patent Publication, US 5349618 A.

[5] Y Jeffrey S, Merrifield, (2001), Study Outlines Reactor Designs That May Be Ready For Deployment By Decade's End, Nuclear News, Vol 44 No 9, August 2001. Hal. 25.

[6] Masrukan, Yatno D.A, Suyoto, Slamet P, Susworo, Setia Permana, Yanlianastuti, (2013), Pengembangan Teknologi Bahan Bakar Reaktor Riset, Prosiding HasilHasil Penelitian Pusat Teknologi Bahan Bakar Nuklir- Batan, 2013. ISSN No. 0854-5561.

[7] Masrukan, M.H Alhasa, Anwar Mukhsin, (2014), Pembuatan Green Pellet U-ZrH Untuk Bahan Bakar PWR, Jurnal IImiah Daur Bahan Bakar Nuklir "Urania", Volume 20 No 1, Febuari 2014, Hal. 23. ISSN No: 0852-4777, Akreditasi No. 395/AU2/P2MI-LIPI/04/2012.

[8] Mohammad Safrudin Yafiedan, Widyastuti, (2014), Pengaruh Variasi Temperatur dan Waktu Tahan Sintering Terhadap Densitas dan Kekerasan pada Mmc W-Cu Melalui Proses Metalurgi Serbuk, Jurnal Teknik Pomits Vol. 3, No. 1, (2014), Hal.45. ISSN No. 2337-3539.

[9] R. Didiek Herhady, R. Sukarsono, (2007), Pengaruh Temperatur dan Waktu Sintering Terhadap Kualitas Bahan Bakar
Kernel $\mathrm{UO}_{2}$ Dalam Furnace Jenis Fluidized Bed". Prosiding Seminar Nasional ke-13 Teknologi dan Keselamatan PLTN Serta Fasilitas Nuklir. Pusat Teknologi Akselerator dan Proses Bahan. ISSN No. 0854 - 2910.

[10] Taufik Usman,(2009), Sintering Temperatur Rendah Atas Kompakan Serbuk Halus $\mathrm{UO}_{2}$ Dengan Variasi Kandungan Pelumas Zn-Stearat, Prosiding Pertemuan dan Presentasi IImiah Daur Bahan Bakar Nuklir, Pusat Teknologi Bahan Bakar Nuklir dan Daur Ulang, Serpong, 13 Oktober 2009. Hal. 41 ISSN No. 14101998.

[11] Ramlan, Ahmad Aminuddin Bama, (2011), Pengaruh Temperatur Dan Waktu Sintering Terhadap Sifat Bahan Porselin Untuk Bahan Elektrolit Padat (Komponen Elektronik), Jurnal Penelitian Sains, Volume 14 No 3, Hal. 22-25. ISSN No. 0854 - 556. 1.

[12] Totemeier Aaron R, Mc Deavit Sean M, (2009), Powder Metallurgical Fabrication of Zirconium Matrix Cermet nuclear Fuels, J Material Science, 2009, 44: 5494-5500.

[13] Zazilatul Khikmiah,dkk, (2013), Pengaruh Variasi Temperatur Sintering Terhadap Sifat Mikroskopik Dan Makroskopik Semen Gigi Nano Zinc Oxide Eugenol, Prosiding Seminar FMIPA Universitas Lampung, 2013.

[14] Tae Kyu Kim, Chong Tak Lee, Dong Seong Sohn, (2008), Sintering Behavior of U-80at \% Zr Powder Compacts in a Vacuum Enviroment, Advance Nuclear Division, Korea Atomic Energy Research Institute, Journal of Nuclear Materials 372(2008) 394-399.

[15] Ahmad Junaidi, Amin Suhadi, (2013), Pengembangan Metode Pembuatan Elektroda Tembaga Karbon Dengan Metalurgi Serbuk, Jurnal Sains Dan Teknologi Indonesia, Vol 15 No 2, Agustus 2013, Hal. 70. Balai Besar Teknologi Kekuatan Struktur, BPPT. 